\title{
The Impact of Teachers' Interventions on Collaborative Problem Solving Interactions in Undergraduate Engineering Classrooms
}

Dr. Saadeddine Shehab, University of Illinois at Urbana - Champaign

A Postdoc Research Associate at the Siebel Center for Design at the University of Illinois at UrbanaChampaign; studies the role of the teacher in implementing and assessing collaborative problem solving in STEM classrooms 


\title{
The Impact of Teachers' Interventions on Collaborative Problem Solving Interactions in Undergraduate Engineering Classrooms
}

\author{
Saadeddine Shehab \\ shehab2@illinois.edu \\ University of Illinois at Urbana-Champaign
}

\section{Introduction}

This evidence-based practice paper examines how the strategies that two graduate teaching assistants (TAs) and three undergraduate course assistants (CAs) used to intervene in the groups' work influenced the quality of students' interactions in the groups during four collaborative problem solving undergraduate engineering discussion sections.

Collaborative problem solving can be defined as "a coordinated, synchronous activity that is the result of a continued attempt to construct and maintain a shared conception of a problem" [1, p.70]. Research shows that the quality of students' interactions that take place during a collaborative problem solving activity under the collaborative, cognitive, and metacognitive dimensions influence the outcomes of the activity [2], [3]. Consequently, when intervening in groups, teachers must implement strategies that can facilitate the occurrence of high quality students' interactions such as elaborating on and negotiating ideas (collaborative dimension), providing explanations, causal elaborations or justifications (cognitive dimension), and monitoring individual or group understanding or progress on the task (metacognitive dimension) [4], [5].

Teachers can foster positive students' interactions during group work [4], [5], [6]. Research studies recommend many strategies that teachers can implement to improve the quality of student interactions [7], [8], [9]. Effective teachers' interventions are characterized by being contingent on any difficulties that the group is facing, but without taking away the need for students to co-construct knowledge as they solve the task [6], [7], [10]. They tend to include dialogic strategies (e.g. asking questions to probe and explore the group's understanding of the task) rather than authoritative or directive strategies (e.g. immediately giving students solution procedures). Researchers argue that dialogic strategies can help teachers understand the students' difficulties and then provide the appropriate support to initiate or improve the quality of students' interactions [7], [11]; however, authoritative or directive strategies may result in extensive support that can decrease the opportunities for the students to interact or participate in high quality interactions [6], [12].

In undergraduate engineering classrooms, TAs are expected to implement various teaching practices such as presenting information, emphasizing certain concepts, communicating with students, and assessing students' outcomes [13]; however, little is known about the strategies that they actually implement during collaborative problem solving activities and the impact of these strategies on the quality of students' interactions. This study addresses this gap in the literature by examining the strategies that two graduate teaching assistants and three undergraduate course assistants used to intervene in the groups' work during four collaborative problem solving undergraduate engineering discussion sections. It also investigates how these strategies influenced the quality of students' interactions in the groups. This study set out to answer the following research questions: 
1) What were the strategies that the TAs and CAs used to intervene with the groups' work?

2) What was impact of these strategies on the quality of students' interactions in the groups?

\section{Methods}

Design

A qualitative exploratory design is used in this study [14], which is a part of a multi-year design-based implementation project [15] that aims to develop tools to support collaborative problem solving in undergraduate engineering courses.

\section{Participants}

Participants were two TAs (Austin \& Joey), three CAs (Tom, Jim, \& Ted), and 45 undergraduate engineering students (29 males and 16 females). The TAs were graduate engineering students and the CAs were undergraduate engineering students who had taken the target course in previous semesters. Neither the TAs nor the CAs had prior teaching experience when they started teaching the discussion sections; they had not attended any professional development on teaching in a collaborative problem solving classroom. However, the faculty member responsible for the course met weekly with all the TAs to discuss the learning goals of each weeks' task.

\section{Data Sources}

The data for this study were collected during four 50-minutes discussion sections that were a required part of an introductory engineering course at a large Midwestern university. The discussion sections took place in a laboratory classroom. Each discussion section was taught by one TA and two CAs (see Table 1). The 14 consented groups, the TAs, and the three CAs were recorded using ceiling mounted cameras and lapel, table or hanging microphones. During all discussion sections, students worked in small groups to solve the same ill-structured, authentic engineering task that was designed using the guidelines designed by the Authors [16]. The task was on 11-inch tablets, with project software installed. Each student had one tablet; tablets of students in the same group were synchronized, so that members of each group worked on and contributed to the same document (see Figure 1).

Table 1

Teachers of the Discussion Sections in the Current Study

\begin{tabular}{lllll}
\hline & Section 1 & Section 2 & Section 3 & Section 4 \\
\hline$T A$ & Austin & Austin & Joey & Joey \\
$C A s$ & Tom \& Ted & Tom \& Jim & Tom \& Jim & Tom \& Ted \\
\hline
\end{tabular}




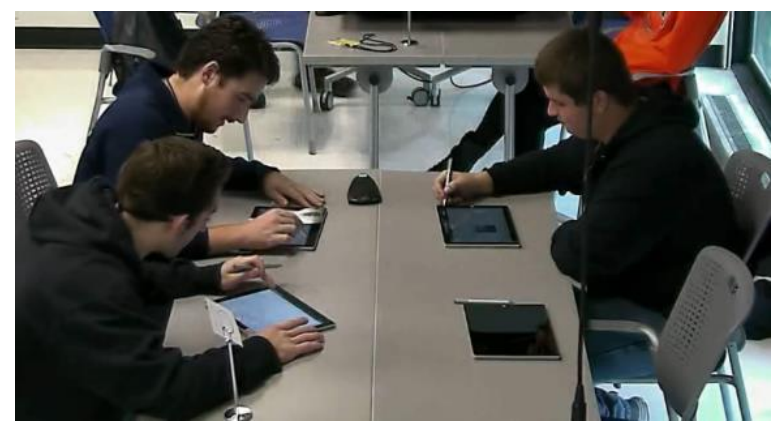

Figure 1: Three students in the same group working on the task

\section{Data Analysis}

The recordings were transcribed for analysis. The analysis focused on the task-related intervention episodes. An intervention episode began when the teacher joined a group and ended when the teacher left this group. Two emergent coding schemes were used to identify the initiating moves and the follow up moves that occurred at the beginning and during an intervention episode. The Initiating Moves Coding Scheme (see Table 2) was applied to the initiating turn by the student, TA or CA. The Follow Up Moves Coding Scheme (see Table 3) was applied to each follow up turn by the teacher that came after the initiating turn in the same intervention episode. To evaluate interrater reliability, two researchers coded all initiating and follow up turns of the intervention episodes that occurred with two of the 14 groups. Cohen's kappa was .95 for the initiating moves and .81 for the follow up moves. Disagreements were discussed to reach agreement. The codes and sequence of the moves in each intervention episode were examined to identify the strategy that teachers used to intervene with the groups' work.

Table 2

The Initiating Move Coding Scheme

\begin{tabular}{|c|c|c|c|}
\hline & Code & \multirow{2}{*}{$\begin{array}{l}\text { Definition } \\
\text { The student asks a question } \\
\text { to clarify something related } \\
\text { to the content of the task }\end{array}$} & \multirow{2}{*}{$\begin{array}{l}\text { Example } \\
\text { "Isn't it like a square } \\
\text { shelf like just one level?" }\end{array}$} \\
\hline \multirow[t]{4}{*}{$\begin{array}{l}\text { Initiation } \\
\text { Move by } \\
\text { Student }\end{array}$} & $\begin{array}{l}\text { Asks a clarification } \\
\text { question }\end{array}$ & & \\
\hline & $\begin{array}{l}\text { Asks a conceptual } \\
\text { question }\end{array}$ & $\begin{array}{l}\text { The student asks a question } \\
\text { about a concept that is } \\
\text { related to the task }\end{array}$ & $\begin{array}{l}\text { "Is there a difference } \\
\text { between a shear force } \\
\text { and a normal force?" }\end{array}$ \\
\hline & $\begin{array}{l}\text { Asks a procedural } \\
\text { question }\end{array}$ & $\begin{array}{l}\text { The student asks a question } \\
\text { about a step that is required } \\
\text { to solve the task }\end{array}$ & $\begin{array}{l}\text { "Do we have to calculate } \\
\text { reaction forces?" }\end{array}$ \\
\hline & Other & Inaudible or unintelligible & \\
\hline $\begin{array}{l}\text { Initiation } \\
\text { Move by } \\
\text { TA/CA }\end{array}$ & Asks a general question & $\begin{array}{l}\text { The TA/CA asks a question } \\
\text { that is related to the group } \\
\text { members' understanding of } \\
\text { the task content, solving }\end{array}$ & $\begin{array}{l}\text { "Do you have an idea of } \\
\text { what the problem is or } \\
\text { what you are trying to } \\
\text { do?" }\end{array}$ \\
\hline
\end{tabular}


procedures, or their progress

on the task

Asks a specific task-

The TA/CA asks a question

"So have you guys

related question

that is related to a specific

step that the group must

calculated the shear

have iterated to solve the

force?"

task

Comments on the

The TA/CA comments on

group's work

the quality of the group

"Interesting work

work Marco!"

Comments on student's

The TA/CA comments on

N/A

or group's

the collaborative behavior

collaborative behavior

of the student or group

Instructs group to do

task-related actions

The TA/CA instructs one or

more students to do or not

to do something related to

the task

"Now you put down what you do to solve for it"

Instructs group to do collaboration-related

The TA/CA instructs one or

$N / A$ actions more students to do or not to do something related to collaboration

Other Inaudible or unintelligible

Table 3

The Follow-up Moves Coding Scheme

\begin{tabular}{ll}
\hline Code & Definition \\
\hline $\begin{array}{l}\text { Provides a simple } \\
\text { answer to a student } \\
\text { question }\end{array}$ & $\begin{array}{l}\text { The TA/CA answers a student's } \\
\text { question without any additional } \\
\text { elaboration or explanation }\end{array}$ \\
$\begin{array}{ll}\text { Provides an elaborated } \\
\text { answer to a student } \\
\text { question }\end{array}$ & $\begin{array}{l}\text { The TA/CA answers a student's } \\
\text { question with additional elaboration } \\
\text { or explanation }\end{array}$
\end{tabular}

Example

Student: "Is that talking about

the shear or the normal

force?"

TA: "Shear force"

Student: "Do we only get one of each?"

TA: "Yes, so those are all the objects that you're working with. You put one of each of those on one of the shelves."

Evaluate/Judges the group work

The TA/CA evaluates or judges the group work

TA: "No, what you guys did here is wrong" 
Reacts to a student's statement

Repeats/Revoices

Asks a student to clarify or repeat idea

Invites students to present their ideas

Explores students' understanding of ideas/concepts/solution procedures Challenges student idea

Provides explicit tips/hints on how to solve the problem Provides an explanation or elaboration

Instructs student or group

Encourages students to collaborate
TA/CA simply accepts, confirms, or rejects students' statements or make neutral statements

TA/CA repeats/revioces a student idea to give the student a pace to follow-up

TA/CA asks a question to clarify something related to what the student was saying

TA/CA invites one or more students to speak up to share ideas/thoughts/reasoning

TA/CA prompts students to say more about a certain concept or problem solving procedure

TA/CA challenges student's idea by asking a question or providing a counter argument that prompts student's thinking

The TA/CA explicitly presents hints or tips on how to solve the problem

TA/CA explains or elaborates on certain concepts or problem solving procedures

TA/CA instructs one or more students to do or not to do something

The TA/CA encourages students to communicate/talk/discuss ideas with each other
Student: "So the shelf is held on the left and right side", TA: "Right, the shelf is held on the left and right side"

Student: "We put everything in the middle and now we're going to calculate it"

TA: "You are calculating it, okay."

Student: "So we are going to find the distribution that fails"

TA: "Huh? say again"

"So what do you guys think?"

TA: "If I cut it just to the right of that 62 newtons going down it, what would it be?"

Student: "So this distribution will fail"

TA: "Are you sure about that?"

TA: "Just put the books in the middle of the shelf and you are on the right track"

"So for this case since we have zero axial or zero forces, it does not really matter"

"Okay so can all of you go to page three? I can explain this to all of you. And then just put your tablets down"

"Just discuss how you want to go about the problem and the assumptions that you want to make" 
Other

No follow up moves
Inaudible or unintelligible

The TA/CA leaves group without

making any follow up moves

besides the initiating move

To identify how the teachers' intervention strategies influenced the quality of students' interaction in the groups, the episodes before and after each intervention episode were marked. Interventions that were preceded and proceeded by off task or quiet task solving episodes and interventions that were preceded by interactive task solving episodes and proceeded by off task or quiet task solving episodes were considered to have a negative impact on quality of students' interactions in the groups. Interventions that were preceded by off task or quiet task solving episodes and proceeded by interactive task solving episodes were considered to have a positive impact on the quality of students' interactions in the groups.

For interventions that were preceded and proceeded by interactive episodes, the turns within an interval of one minute before and one minute after the time when the intervention occurred were coded under the cognitive, collaborative and metacognitive dimensions using three coding schemes that were adapted from [7], [17], [18] respectively. Then, the coded turns were examined and compared. Proportions were calculated in cases where there was a large difference between the number of turns that were present one minute before the intervention occurred and those that were present one minute after the intervention occurred. Interventions that were directly followed by the appearance or increase in the number of high quality collaborative problem solving turns in at least one dimension were considered to have a positive impact on the quality of students' interactions. Interventions that were proceeded by the disappearance or decrease in the number of high quality turns in at least one dimension were considered to have a negative impact on the quality of students' interactions. Interventions that were proceeded by approximately the same number of high quality turns per each dimension were considered to have a neutral impact on the quality of students' interactions. Interventions that had a positive impact on the quality of the students' interactions under at least one of the three dimensions and a negative impact on the quality of the students' interactions under one or both of the other dimensions was considered to have a mixed impact on the quality of the collaborative problem solving interactions of the group.

\section{Results}

There was a total of 61 task-related teacher intervention episodes across the four discussion sections. Table 4 shows the strategies that the teachers used during these episodes to intervene with the groups' work and the impact of these strategies on the quality of students' interactions in the groups.

Table 4

The Impact of the Strategies that the Teachers Used to Intervene with the Groups' Work

Impact on Students' Interactions

Strategy $\quad$ Positive Negative Neutral Mixed




$\begin{aligned} & \text { Provided elaborated answers to students' questions or } \\ & \text { explanations of problem solving procedures }\end{aligned}$
$\begin{aligned} & \text { Clarified task related issues by providing simple } \\ & \text { answers to students' clarification questions }\end{aligned}$
$\begin{aligned} & \text { Probed and explored students' understandings until } \\ & \text { they figured out their next step }\end{aligned}$
$\begin{aligned} & \text { Checked progress on task without further commenting } \\ & \text { or prompting }\end{aligned}$
$\begin{aligned} & \text { Checked progress on task and provided a hint for } \\ & \text { solving the task }\end{aligned}$
$\begin{aligned} & \text { Explicitly encouraged the group members to work } \\ & \text { together }\end{aligned}$

\section{Discussions and Conclusions}

Findings from the analysis of the task-related interventions showed that providing elaborated answers to students' questions or explanations or problem solving procedures to the groups tended to negatively impact the quality of students' interactions in the groups. Providing extensive task-related support may have interrupted the group discussions or may have taken away the need for students to interact and co-construct knowledge as they solve authentic problems by removing the challenging aspects of the task. These findings align with prior research that shows direct task-related support may reduce the chances for the group members to interact or participate in high quality interactions [9], [12].

Clarifying task related issues by providing simple answers to students' clarification questions or checking the group's task progress and providing a hint to solve the task tended to positively impact the quality of students' interactions in the groups. These strategies may have given the groups just enough explicit-task related support that is adaptive to the group's needs for students to initiate interactions or co-construct of knowledge. These findings align with prior research that found that offering only few content-related ideas or prompts when needed without making evaluative comments can positively impact collaborative problem solving of authentic tasks [7]. Also, probing and exploring students' understanding until they figure out their next step tended to positively impact the quality of students' interactions in the groups. This supporting strategy may have dialogically scaffolded the group's thinking [11] by providing task related support that allowed the students to identify their mistakes or figure out how to solve the task.

Explicitly encouraging the group members to work together was only used in one intervention episode. It had a positive impact on the quality of students' interactions in the group. Checking the group's task progress without further commenting or prompting on the students' responses had different impacts on the quality of students' interactions in the groups. These findings suggest that in some instances, this strategy may have not provided the groups with the 
appropriate support to interact or may have interrupted the discussion of the groups. In other instances, this strategy may have triggered the group members to interact.

Table 4 also shows that some strategies had neutral or mixed impact on the quality of students' interactions in the groups. This is because previous findings from this work [19] showed that the teachers were not purposefully monitoring the quality of students' interactions and were not intervening with the groups to improve the quality of these interactions. Consequently, more research is needed to assess the impact of teaching strategies that intend to positively impact the quality of students' interactions in the groups. However, findings from this study can inform teachers' preparation programs. Specifically, they provide concrete guidelines about what teaching assistants can do and what they can avoid when intervening with the groups' work to improve the quality of students' interactions in collaborative problem solving engineering classrooms. 


\section{References}

[1] J. Roschelle and S. Teasley, "The construction of shared knowledge in collaborative problem solving", in Computer Supported Collaborative Learning, 1995, pp. 69-96.

[2] B. Barron, "When Smart Groups Fail," Journal of the Learning Sciences, vol. 12, no. 3, pp. 307-359, 2003.

[3] C. Kaendler, M. Wiedmann, N. Rummel, and H. Spada, "Teacher Competencies for the Implementation of Collaborative Learning in the Classroom: a Framework and Research Review", Educational Psychology Review, vol. 27, no. 3, pp. 505-536, 2014. Available: 10.1007/s10648-014-9288-9.

[4] R. Gillies, "Promoting academically productive student dialogue during collaborative learning", International Journal of Educational Research, vol. 97, pp. 200-209, 2019. Available: 10.1016/j.ijer.2017.07.014.

[5] A. van Leeuwen and J. Janssen, "A systematic review of teacher guidance during collaborative learning in primary and secondary education", Educational Research Review, vol. 27, pp. 71-89, 2019. Available: 10.1016/j.edurev.2019.02.001.

[6] N. Webb et al., "'Explain to your partner': teachers' instructional practices and students' dialogue in small groups", Cambridge Journal of Education, vol. 39, no. 1, pp. 49-70, 2009. Available: 10.1080/03057640802701986.

[7] C. Hmelo-Silver and H. Barrows, "Facilitating Collaborative Knowledge Building", Cognition and Instruction, vol. 26, no. 1, pp. 48-94, 2008. Available: 10.1080/07370000701798495.

[8] R. Hofmann and N. Mercer, "Teacher interventions in small group work in secondary mathematics and science lessons", Language and Education, vol. 30, no. 5, pp. 400-416, 2015. Available: 10.1080/09500782.2015.1125363.

[9] N. Webb, "The teacher's role in promoting collaborative dialogue in the classroom", British Journal of Educational Psychology, vol. 79, no. 1, pp. 1-28, 2009. Available: 10.1348/000709908x380772.

[10] N. Webb, M. Franke, M. Ing, A. Turrou, N. Johnson, and J. Zimmerman, "Teacher practices that promote productive dialogue and learning in mathematics classrooms", International Journal of Educational Research, vol. 97, pp. 176-186, 2019. Available: 10.1016/j.ijer.2017.07.009.

[11] S. Rojas-Drummond, O. Torreblanca, H. Pedraza, M. Vélez and, K. Guzmán, "'Dialogic scaffolding': Enhancing learning and understanding in collaborative contexts", Learning, Culture and Social Interaction, vol. 2, no. 1, pp. 11-21, 2013. Available:

10.1016/j.lcsi.2012.12.003. 
[12] K. Hogan, B. Nastasi and, M. Pressley, "Discourse Patterns and Collaborative Scientific Reasoning in Peer and Teacher-Guided Discussions", Cognition and Instruction, vol. 17, no. 4, pp. 379-432, 1999. Available: 10.1207/s1532690xci1704_2.

[13] J. Luft, J. Kurdziel, G. Roehrig, and J. Turner, "Growing a garden without water: Graduate teaching assistants in introductory science laboratories at a doctoral/research university", Journal of Research in Science Teaching, vol. 41, no. 3, pp. 211-233, 2004. Available: 10.1002/tea.20004.

[14] C. Marshall and G. Rossman, Designing qualitative research. 2016.

[15] W. Penuel, B. Fishman, B. Haugan Cheng and, N. Sabelli, "Organizing Research and Development at the Intersection of Learning, Implementation, and Design", Educational Researcher, vol. 40, no. 7, pp. 331-337, 2011. Available: 10.3102/0013189x11421826.

[16] S. Shehab, E. Mercier, M. Kersh, G. Juarez, and, H. Zhao, "Designing Engineering Tasks for Collaborative Problem Solving," in Making a Difference-Prioritizing Equity and Access in CSCL: The 12th International Conference on Computer Supported Collaborative Learning, 2017, B.K. Smith, M. Borge, E. Mercier, K.Y. Lim (Eds). Philadelphia: The International Society of the Learning Sciences.

[17] S. Higgins, E. Mercier, L. Burd and, A. Joyce-Gibbons, "Multi-touch tables and collaborative learning", British Journal of Educational Technology, vol. 43, no. 6, pp. 1041-1054, 2011. Available: 10.1111/j.1467-8535.2011.01259.x.

[18] S. Selcen Guzey and M. Aranda, "Student Participation in Engineering Practices and Discourse: An Exploratory Case Study", Journal of Engineering Education, vol. 106, no. 4, pp. 585-606, 2017. Available: 10.1002/jee.20176.

[19] S. Shehab and E. Mercier, "Exploring teaching and course assistants' interventions with groups during collaborative problem solving," in Proceedings of the 13th International Conference of Computer Supported Collaborative Learning (CSCL), Lyons, France, June 2019. 